\title{
Estéticas emergentes para la defensa de la vida
}

\section{Emerging Aesthetics for Defense of Life}

\section{Marco Aguilera Enríquez \\ marcoaguilera1711@gmail.com}

Entre el 25 de agosto y el 15 de septiembre del 2018 se llevó a cabo en la ciudad de Chihuahua el $2^{\circ}$ Festival de Arte Nuevo, un proyecto de la Secretaría de Cultura y la Facultad de Artes de la Universidad Autónoma de Chihuahua que buscaba construir espacios de diálogo y reflexión en torno al desplazamiento, el viaje y la migración. Además de la presentación de proyectos de artes visuales, arte sonoro, nuevas tecnologías y artes escénicas, el Festival incluyó eventos de investigación transdisciplinar. En el marco de estos últimos, la artista plástica Angélica Chávez Blanco propuso la participación del doctor Rafael Mondragón para la impartición de un taller.

Así surgió el taller Estéticas emergentes para la defensa de la vida; la primera sesión fue: "La razón ética ante la estética del terror: vulnerabilidad resistente y sensibilidad afectiva”. En ella se invitó al público a un viaje conceptual, histórico y reflexivo alrededor de los sentidos de la violencia en el México actual. Se partió del diagnóstico sobre nuestro país presentado por el Tribunal Permanente de los Pueblos. A partir de las aportaciones conceptuales de Juan Carlos Marín, Johan Galtung y Martin Luther King, se analizó la hipótesis de que la violencia es un dispositivo sociopolítico construido históricamente; por ello, se puede investigar su racionalidad y desarticular su dinámica. De igual manera se propuso recuperar las ideas de Paulo Freire sobre la cultura del silencio y retomar su conceptualización de los procesos de organización colectiva para pensar las potencialidades del arte. En la misma línea se retomaron los planteamientos de Reinaldo Laddaga, Ileana Diéguez y Augusto Boal sobre el arte como espacio para la construcción de "comunidades experimentales", los 
"escenarios liminales" construidos en los espacios de lucha social y el papel del "espacio estético" como lugar donde se puede observar lo que ha sido invisibilizado. En la última parte se reflexionó sobre la experiencia llevada a cabo por Alfonso Díaz Tovar y Paola Ovalle en el Colectivo RECo, donde convergen el arte comunitario y el resguardo de la memoria colectiva. A partir de ella se habló del sentido del arte como espacio para la elaboración de preguntas abiertas sobre el dolor, el futuro y la justicia. Las acciones culturales son espacios prefigurativos de relaciones sociales alternativas y el espacio estético puede volverse una zona liminar desde la cual es posible una exploración práctica sobre lo común y la comunidad.

El segundo día del taller tuvo como título "Filiación, transmisión, restitución e identidad". Se pusieron en relación algunos planteamientos elaborados por las Abuelas de la Plaza de Mayo con la obra de Sara Uribe, Antígona González. Se reflexionó sobre el sentido de una consigna feminista contemporánea, "Maternar es político", y desde ella se habló de la filiación como una tarea política importante en tiempos de destrucción de los vínculos sociales. Se reflexionó, además, sobre las dimensiones psicosociales del dolor y la búsqueda de maneras nuevas de narrar y renarrar la experiencia subjetiva. Se exploraron algunas maneras de construcción de encuentros íntimos y reveladores y se remitió a las ideas de Shaday Larios sobre cómo construir una perspectiva dignificante del pasado a partir de la recuperación de la memoria de algunos objetos amados.

El último día de trabajo se tituló "La ética de la ternura frente a la estética de la crueldad. Recuperación de la palabra y elaboración de proyectos de futuro". En ella se reflexionó en torno del catálogo de la exposición "Infancia y dictadura", coordinada por Patricia Castillo, la cual gira alrededor de la memoria de la infancia durante la dictadura chilena, También se habló de la obra de teatro Cosas pequeñas y extraordinarias de Daniela Arroio y Micaela Gramajo. Se habló del poder sanador de la ficción, la metáfora y la fantasía. El taller cerró con una referencia a los planteamientos de la ética y política de la ternura propuestos por el psicoanalista Fernando Ulloa.

El neuropsiquiatra Jorge Barudy una vez escribió: "No tratamos a nadie, no curamos a nadie, si algo tenemos que ver en la disminución del sufrimiento humano es justamente en la medida en que somos capaces de facilitar la creación de espacios de solidaridad donde la humanización sea posible". El taller reseñado nos recordó que, si bien no transforma- 
remos el mundo de un día para otro, procesos de transformación ya han iniciado y se manifiestan en nuestra vida cotidiana.

\section{Marco Aguilera Enríquez}

Psicólogo y estudiante de derecho. Perito en psicología jurídica y forense en el Tribunal Superior de Justicia del Estado de Chihuahua, con formación especializada por parte del Alto
Comisionado de Naciones Unidas en casos de tortura, tratos crueles, inhumanos y degradantes. Secretario general del Colegio de Psicólogos del Estado de Chihuahua y profesor de la Universidad del Valle de México y el Claustro Universitario de Chihuahua. Interesado en temas de convergencia entre la psicología y el arte, así como en la construcción de diálogos interdisciplinarios. 